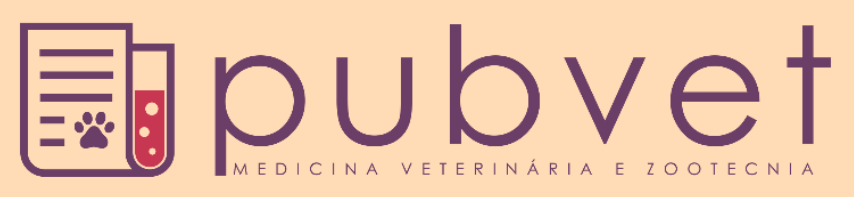

https://doi.org/10.31533/pubvet.v15n08a876.1-8

\title{
Estudo retrospectivo dos níveis séricos de ureia e creatinina em cães com lesão renal crônica tratados com célula tronco
}

\author{
Luiz Fernando Lucas Ferreira ${ }^{*} \oplus$, Camila Molan Botton ${ }^{2} \Phi$, Tais Soares Magalhães ${ }^{2} \Phi$, Bruna \\ Ferraz Calhau ${ }^{3 \mathbb{9}}$, Enrico Jardim Clemente Santos ${ }^{4 \mathbb{9}}$, Caroline Pinho Winck ${ }^{5 \mathbb{G}}$, Pâmela Karine \\ Félix de Souza ${ }^{6}$
}

${ }^{1}$ Professor da PUC Minas, Departamento de Medicina Veterinária. Betim - MG Brasil.

${ }^{2}$ Graduandas do Curso de Medicina Veterinária da PUC Minas Betim.

${ }^{3}$ Graduanda do Curso de Medicina Veterinária da PUC Minas Praça da Liberdade.

${ }^{4}$ Biocientísta. Mestre, Doutor, Pós-Doutor. Diretor de Inovação Tecnológica da CELLTROVET.

${ }^{5}$ Bióloga, Mestre. Gestora do Laboratório de Biotecnologia da CELLTROVET.

${ }^{6}$ Graduanda do Curso de Medicina Veterinária do Centro Universitário de Belo Horizonte. Belo Horizonte - MG Brasil.

*Autor para correspondência, E-mail: lfvet@hotmail.com

Resumo: Realizou-se um estudo retrospectivo com o objetivo de compilar e salientar informações do histórico clínico e dos exames laboratoriais de ureia e creatinina de pacientes submetidos à terapia celular, para tratamento de doença renal crônica. Foram selecionados 18 cães atendidos no período entre 01/01/2012 e 10/01/2016 com doença renal crônica e tratados com célula tronco. A maior parte dos animais estavam na faixa etária superior a 10 anos. $\mathrm{O}$ estudo sugere que a terapia celular para tratamento de doença renal crônica tem resultado positivo. Os animais com maior resposta após o tratamento foram aqueles classificados em IRIS I e IRIS II, pois o parênquima renal estava mais preservado. Com relação aos animais classificados em IRIS III, 55\% responderam positivamente ao tratamento, diminuindo os níveis séricos de ureia. Os pacientes classificados em IRIS IV não demonstraram a mesma resposta dos grupos anteriores, pois o parênquima já estava muito comprometido e a doença progrediu.

Palavras-chave: cães, células tronco mesenquimais, doença renal, terapia celular

\section{Retrospective study of serum urea and creatinine in dogs with chronic renal failure treated with stem cells}

\begin{abstract}
It was executed a retrospective study to compile and highlight information from the clinical history and laboratory exams of urea and creatinine in patients undergoing cell therapy for the treatment of chronic kidney disease. The sample consisted of 18 cases of dogs attended at the Clínica Veterinária Professor Israel, in the period between 01/01/2012 and 01/10/2016 with chronic renal disease and that were treated with stem cells. Most animals were older than 10 years, there was not a predisposition to one sex and $55 \%$ were diagnosed with other comorbidities. The study suggests that in general, cell therapy for the treatment of chronic kidney disease has a positive result. Animals with better results after treatment were those classified as IRIS I and IRIS II since the renal parenchyma was more preserved. Referring to animals classified as IRIS III, 55\% also responded positively to the treatment, decreasing the serum levels of urea. However, animals classified as IRIS IV did not demonstrate the same results, as the parenchyma had been severely compromised and the disease had progressed.
\end{abstract}

Keywords: cell therapy, dogs, kidney disease, mesenchymal stem cells 


\title{
Estudio retrospectivo de los niveles séricos de urea y creatinina en perros con insuficiencia renal crónica tratados con células madre
}

\begin{abstract}
Resumen: Se realizó un estudio retrospectivo con el fin de recopilar y resaltar información sobre la historia clínica y las pruebas de laboratorio para urea y creatinina en pacientes sometidos a terapia celular para el tratamiento de la enfermedad renal crónica. Se seleccionaron dieciocho perros atendidos entre el 01/01/2012 y el 01/10/2016 con enfermedad renal crónica y tratados con células madre. La mayoría de los animales tenían más de 10 años. El estudio sugiere que la terapia celular para el tratamiento de la enfermedad renal crónica tiene un resultado positivo. Los animales con mayor respuesta tras el tratamiento fueron los clasificados como IRIS I e IRIS II, ya que el parénquima renal estaba más conservado. Con respecto a los animales clasificados como IRIS III, el 55\% respondió positivamente al tratamiento, disminuyendo los niveles de urea sérica. Los pacientes clasificados como IRIS IV no mostraron la misma respuesta que los grupos anteriores, ya que el parénquima estaba muy comprometido y la enfermedad avanzaba.
\end{abstract}

Palabras clave: células madre, mesenquimales, enfermedad renal, perros, terapia celular

\section{Introdução}

A doença renal crônica é uma condição patológica em que ocorre lesão renal persistente pelo período mínimo de três meses. Um ou ambos os rins tem perda de massa funcional e a taxa de filtração glomerular diminui em até 50\% em comparação com a filtração de um rim saudável (Brum et al., 2012; Silva et al., 2008; Waki et al., 2010). Essa enfermidade está entre uma das causas mais significativas de morte e incapacidade em cães e pode ser secundária a outras doenças como erliquiose e leishmaniose. Possui prevalência de até $7 \%$, porém, como é uma doença silenciosa e de curso gradual, esse número pode ser maior devido à subnotificações (Waki et al., 2010).

Na rotina clínica veterinária é preconizado o tratamento suporte, visando à estabilização do quadro clínico e à melhoria da qualidade de vida do paciente, já que as lesões são irreversíveis (Rufato et al., 2011). O uso de célula tronco tem sido uma nova alternativa para o tratamento e vem sendo testado em cães e gatos, se mostrando capaz de reverter as lesões renais sem grandes efeitos colaterais (Morigi \& Benigni, 2013).

O transplante de célula tronco mesenquimal derivada de tecido adiposo visa contribuir para a melhoria da qualidade de vida de cães acometidos por doença renal crônica, através da estabilização e possível reversão das lesões renais (Morigi \& Benigni, 2013). Essa terapia não entra na pauta de discussão ética a respeito do uso de célula tronco, dado que, as mesmas são de origem mesenquimal, retiradas de fragmentos de gordura (Zuttion et al., 2013). A coleta é realizada em cirurgias eletivas de castração de pacientes jovens e saudáveis com a autorização do guardião. $\mathrm{O}$ tecido adiposo permite facilidade na coleta, não causa comprometimento para saúde do doador e permite a obtenção de grandes quantidades de célula tronco (Levin et al., 2019).

O objetivo desse trabalho foi analisar a eficácia do uso de células tronco mesenquimais derivadas de tecido adiposo para o tratamento de doença renal em cães. Foram avaliados os níveis plasmáticos de ureia e creatinina, principais marcadores da função renal, para observar quais as respostas obtidas após o transplante celular.

\section{Material e métodos}

Foram incluídos no estudo os cães submetidos à terapia celular para tratamento de doença renal crônica, atendidos na Clínica Veterinária Professor Israel, situada na rua Raul Pompeia, 54, Carmo, Belo Horizonte, no período entre 01/01/2012 à 10/03/2016.

Os pacientes tratados com célula tronco foram previamente selecionados no sistema de dados da clínica e utilizou-se como critério de inclusão para o estudo somente os casos em que o transplante celular foi voltado para o tratamento de doença renal crônica, totalizando 18 casos. Foram analisadas as distribuições quanto à faixa etária, existência de comorbidades e grau de lesão renal de acordo com a 
classificação adotada pela Sociedade Internacional de Interesse Renal. Para avaliação quanto a resposta à terapia, foram avaliados os parâmetros bioquímicos de ureia e creatinina séricos, comparando um exame antes e após a realização do transplante celular.

Os exames de avaliação de ureia e creatinina sérica foram realizados no laboratório de patologia da Clínica Veterinária Professor Israel.

Os dados foram analisados, tabelados e os resultados demonstrados graficamente.

\section{Resultados e discussão}

Para análise dos resultados, os 18 pacientes foram divididos em quatro grupos de acordo com a classificação proposta pela Sociedade Internacional de Interesse Renal (IRIS).

\section{Grupo de animais classificados como IRIS I}

De acordo com a classificação IRIS (2015), o estágio de classificação I refere-se aos valores séricos de creatinina menores que $1,4 \mathrm{mg} / \mathrm{dL}$. Trata-se de um paciente não azotêmico que apresenta alguma anormalidade renal, como concentração urinária inadequada, proteinúria renal, alterações à palpação renal e exames de imagem ou biópsia alterados. Na amostra de 18 pacientes, apenas o paciente 17 foi classificado como IRIS I.

Trata-se de um paciente com 12 anos e cardiopata. Observando o gráfico 1, pode-se verificar que no primeiro exame após o transplante de célula tronco o valor sérico de ureia diminuiu de $133 \mathrm{mg} / \mathrm{dL}$ para $114 \mathrm{mg} / \mathrm{dL}$ e esses níveis séricos continuaram diminuindo, chegando a $40,0 \mathrm{mg} / \mathrm{dL}$, portanto atingiu os parâmetros de normalidade.

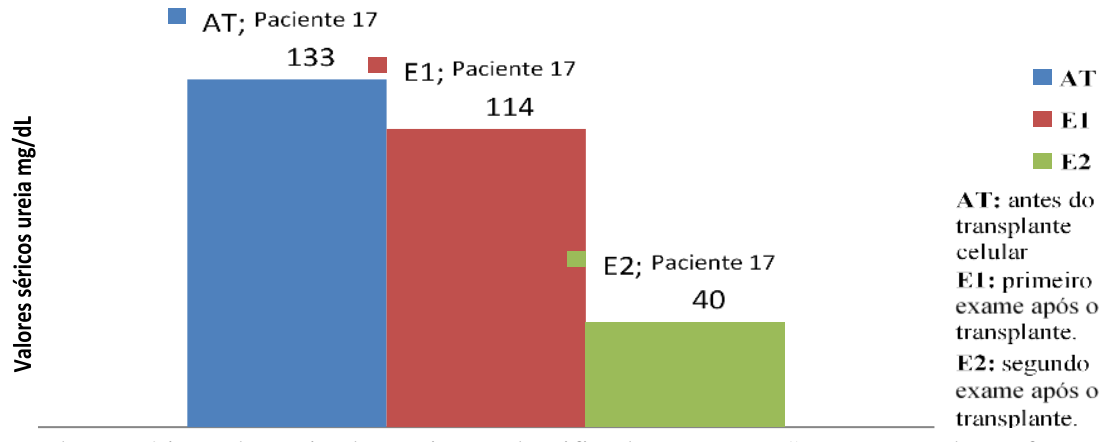

Gráfico 1. Valores séricos de ureia do paciente classificado como IRIS I. Esses valores foram obtidos em avaliações realizadas antes do transplante celular, no primeiro exame após o transplante e no segundo exame após o transplante.

No gráfico 2, referente à progressão dos valores de creatinina antes e após a terapia celular, é possível notar um aumento de $0,1 \mathrm{mg} / \mathrm{dL}$ no primeiro exame após o tratamento e diminuição de $0,2 \mathrm{mg} / \mathrm{dL}$ no segundo exame, atingindo também os parâmetros de normalidade.

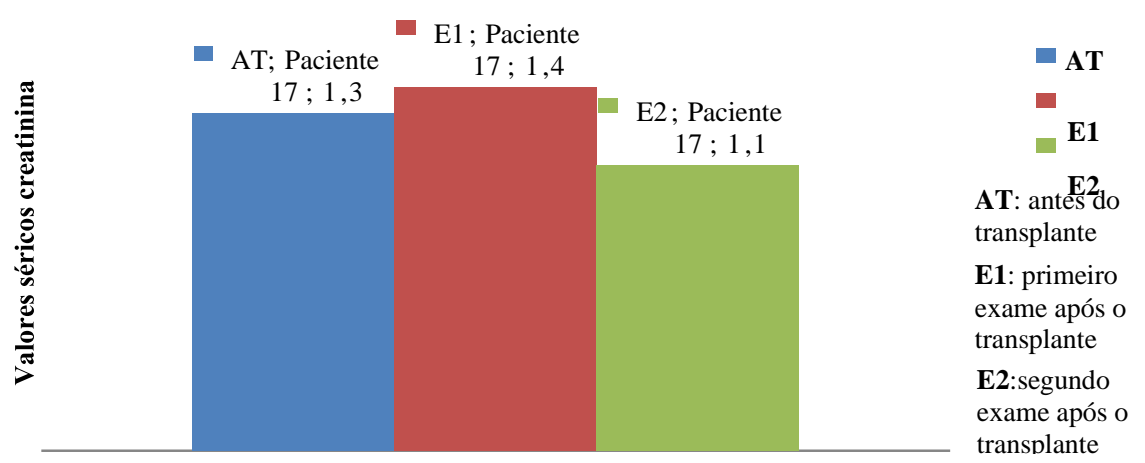

Gráfico 2. Valores séricos de creatinina do paciente classificado como IRIS I. Esses valores foram obtidos em avaliações realizadas antes do transplante celular, no primeiro exame após o transplante e no segundo exame após o transplante. 
Por se tratar de um paciente no primeiro estágio da doença, com parênquima renal ainda preservado, a quimiotaxia para as células tronco foi favorecida (Monteiro et al., 2010), sugerindo o resultado obtido.

\section{Grupo de animais classificados como IRIS II}

Os animais classificados em IRIS II são aqueles com valores séricos de creatinina entre 1,4 e 2,0 $\mathrm{mg} / \mathrm{dL}$, e apresentam discreta azotemia, poliúria e polidipsia (IRIS, 2015). Na amostra de 18 animais, 6 pacientes estavam no estágio IRIS II.

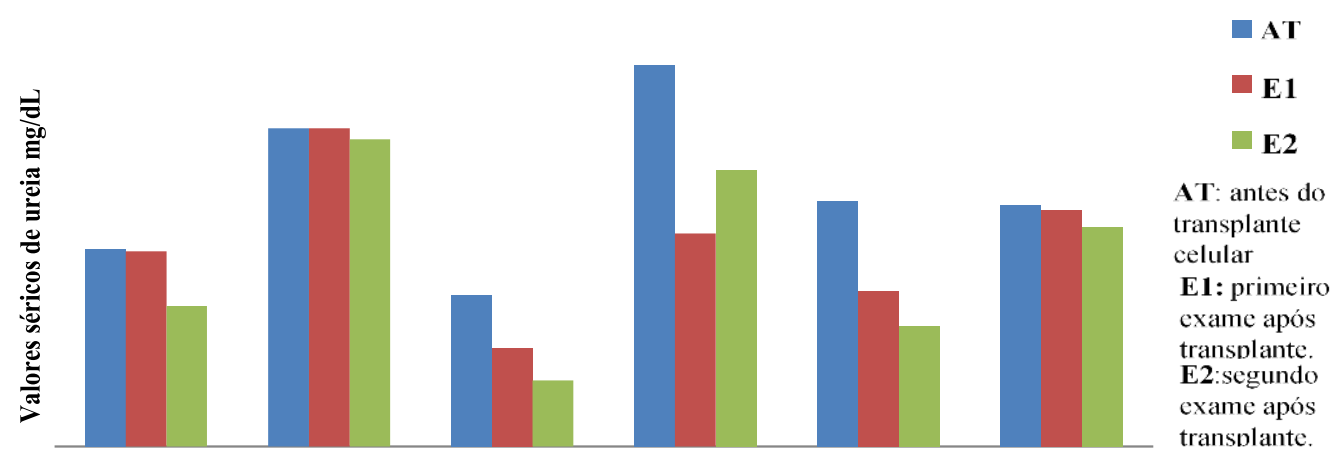

Gráfico 3 - Valores séricos de ureia dos pacientes classificados como IRIS II. Esses valores foram obtidos em avaliações realizadas antes do transplante celular, no primeiro exame após o transplante e no segundo exame após o transplante

Gráfico 4. Valores séricos de ureia dos pacientes classificados como IRIS II. Esses valores foram obtidos em avaliações realizadas antes do transplante celular, no primeiro exame após o transplante e no segundo exame após o transplante.

Todos os pacientes tiveram redução nos valores séricos de ureia após o tratamento com células tronco. Espera-se que esse estágio da doença ainda possibilite uma boa resposta à terapia, devido à ausência de graves lesões nos rins, similar ao que foi observado por Xing et al. (2014).

Em relação aos valores de creatinina sérica, 4 pacientes reduziram os valores, sendo que o paciente 10 e o paciente 16 alcançaram os parâmetros de normalidade. Apesar do tratamento, dois animais apresentaram aumento sérico de creatinina. Esse resultado pode ser justificado pela comorbidade presente

no paciente 6 (cardiopatia e hipertensão) e pelo catabolismo proteico e possível dieta inadequada no paciente 18. De acordo com Bortolotto (2008), os casos de hipertensão arterial tem ligação com a doença cardíaca e renal, podendo ser a causa ou a consequência desta. Essa comorbidade pode ter sido a razão pela qual esse paciente não teve a mesma resposta que os demais. Apesar disso, esses animais tiveram a qualidade de vida aumentada, pois ocorreu melhora da disposição, aumento de apetite e ausência de vômito e diarreia.

\section{Grupo de animais classificados como IRIS III}

O estágio III da classificação IRIS é definido pela presença de azotemia moderada com valores de creatinina sérica entre 2,1 a $5,0 \mathrm{mg} / \mathrm{dL}$. Podem ser observada manifestações sistêmicas da perda de função renal e a progressão da doença está ligada tanto à autoperpetuação (progressão natural da doença) quanto à causas desencadeantes (Waki et al., 2010).

A maior parte dos pacientes tinham mais de 10 anos, com exceção dos pacientes 13,15 e 14, com idades de 3, 7 e 9 anos respectivamente. Dos nove pacientes, houve uma redução significativa em 5 pacientes, diminuição sútil em 1 paciente e aumento nos 3 pacientes restantes.

Com relação à creatinina, cinco animais diminuíram significativamente os valores séricos, dentre eles os pacientes $1 \mathrm{e} 2$ atingiram o valor normal de creatinina. Os demais pacientes tiveram aumento dos valores.

Por se tratar de animais em estágio mais avançado da doença, a resposta à terapia celular pode ser dificultada. O catabolismo proteico e a possível dieta inadequada também prejudicam a redução dos níveis séricos de ureia e creatinina (Leal et al., 2008). 


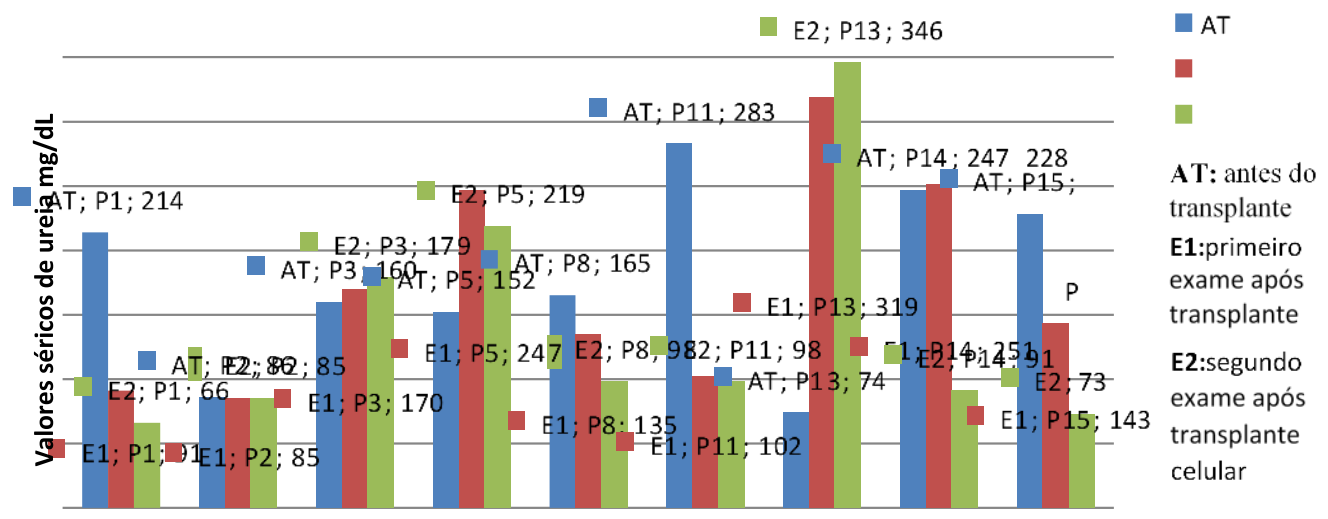

Gráfico 5. Valores séricos de ureia dos pacientes classificados como IRIS III. Esses valores foram obtidos em avaliações realizadas antes do transplante celular, no primeiro exame após o transplante e no segundo exame após o transplante.

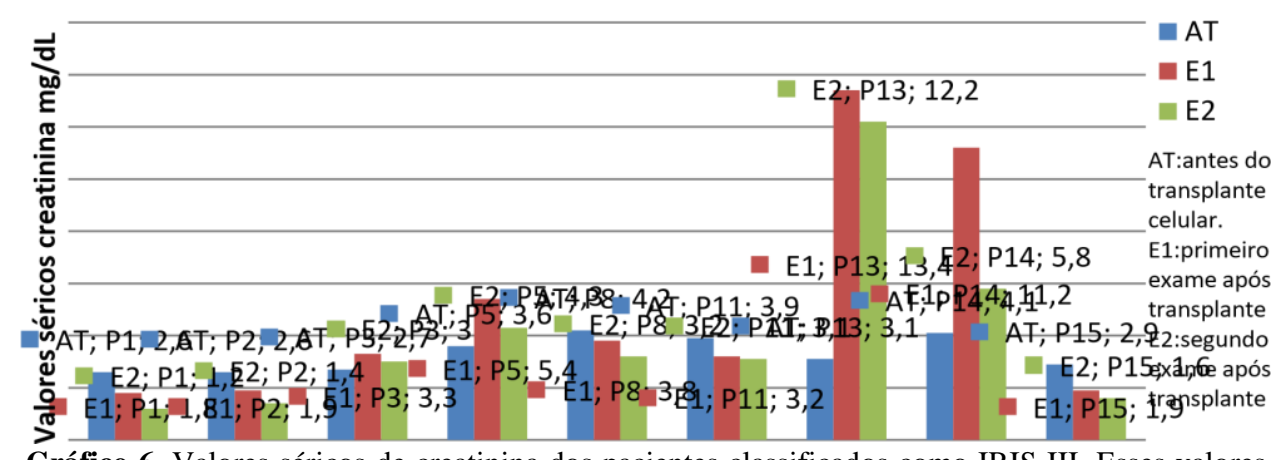

Gráfico 6. Valores séricos de creatinina dos pacientes classificados como IRIS III. Esses valores foram obtidos em avaliações realizadas antes do transplante celular, no primeiro exame após o transplante e no segundo exame após o transplante.

O paciente 3 além das causas acima salientadas, apresentava cardiopatia, esse quadro vai ao encontro do resultado obtido, fato este também observado por Lima et al. (2010).

\section{Grupo de animais classificados como IRIS IV}

O quarto estágio da doença renal crônica caracteriza-se pela presença de uma forte azotemia e creatinina sérica com valor superior a $5,0 \mathrm{mg} / \mathrm{dL}$. Nessa fase o paciente demonstra uma perda significativa da função renal e pode progredir para falência renal (Waki et al., 2010).

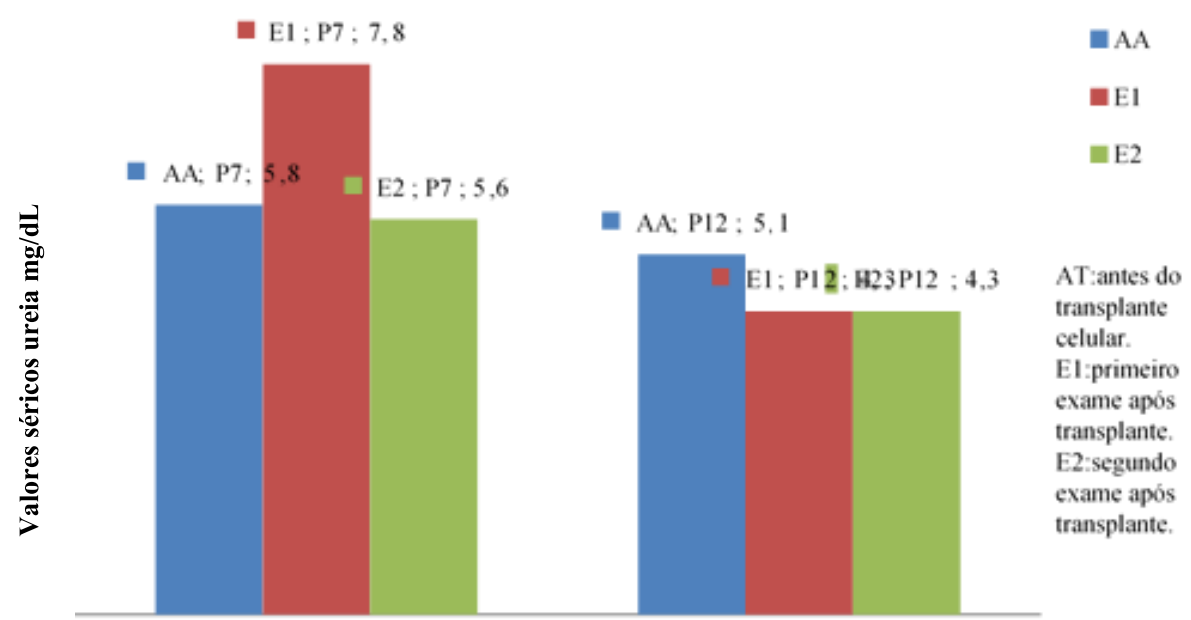

Gráfico 7. Valores séricos de ureia dos pacientes classificados como IRIS IV. Esses valores foram obtidos em avaliações realizadas antes do transplante celular, no primeiro exame após o transplante e no segundo exame após o transplante. 


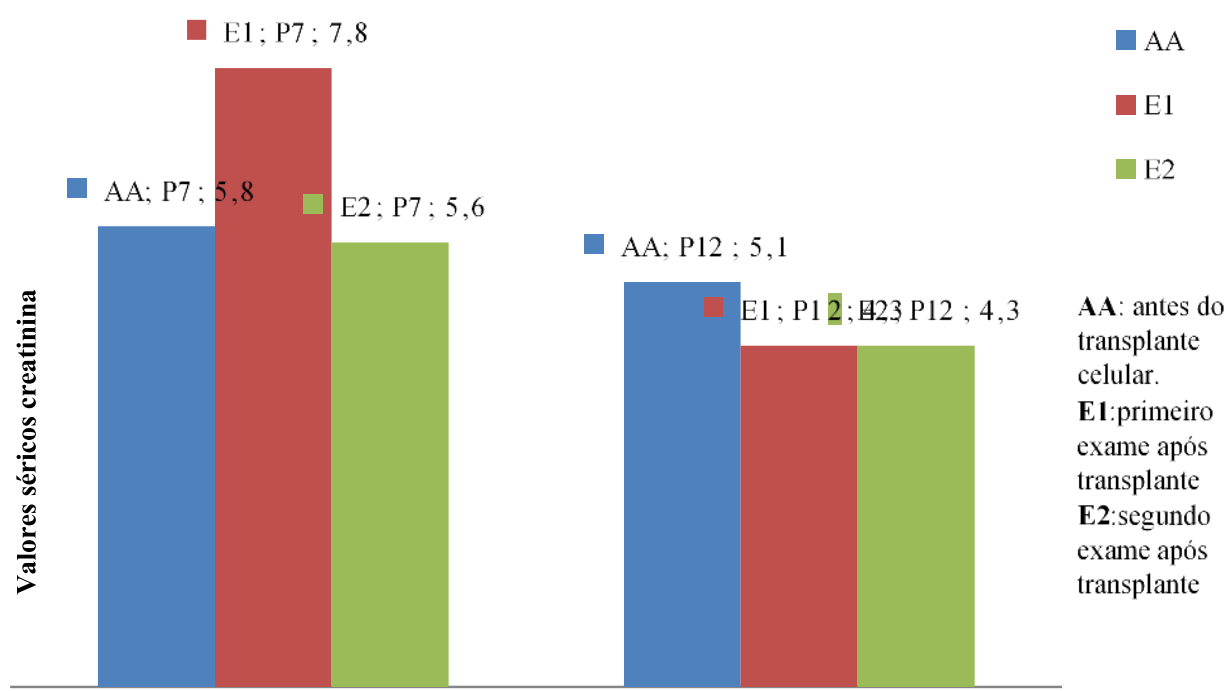

Gráfico 8. Valores séricos de creatinina dos pacientes classificados como IRIS IV. Esses valores foram obtidos em avaliações realizadas antes do transplante celular, no primeiro exame após o transplante e no segundo exame após o transplante.

O paciente "7" tinha 10 anos e nenhuma comorbidade e, apesar do tratamento, teve aumento da ureia sérica. O paciente " 12 " tinha 7 anos e apresentou sutil redução da ureia sérica após a terapia, mas a concentração continuou acima do valor da normalidade.

Com relação à creatinina, apesar de haver uma tênue redução dos valores, ambos pacientes continuaram com os parâmetros acima da normalidade e no mesmo estágio de classificação IRIS.

Como citado anteriormente, o estágio IV é o mais grave da classificação da doença renal, dificultando respostas positivas aos tratamentos. Ainda assim, o paciente 12 apresentou uma sutil redução nos níveis de ureia e creatinina. Esse animal possuía erlichiose, doença que leva a alterações renais devido ao estímulo constante do sistema imunológico do animal contra o patógeno (Isola et al., 2012). Sugere-se que os resultados obtidos são decorrentes também do tratamento da comorbidade, possível causa da lesão renal.

\section{Média dos Valores de Ureia e Creatinina em cada grupo IRIS}

O Gráfico 9 mostra a média dos valores de ureia de acordo com cada grupo da classificação IRIS.

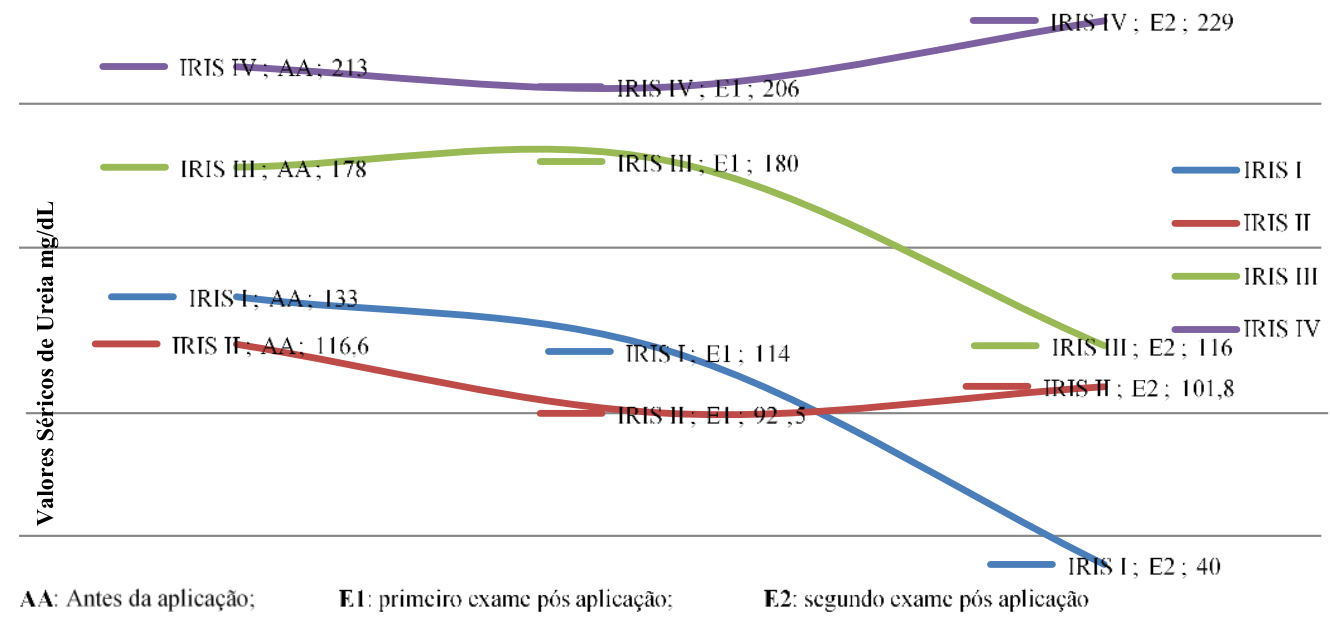

Transplante de célula tronco

Gráfico 9. Gráfico referente à média dos valores séricos de ureia em toda a amostra de acordo com cada estágio da classificação IRIS.

Os pacientes do grupo IRIS I e IRIS III apresentaram redução na média dos valores de ureia. Pacientes do grupo IRIS II apresentaram sutil redução na média dos valores e os animais do grupo IRIS 
IV mostraram um aumento na média. O Gráfico 10 indica a média dos valores de creatinina em cada grupo da classificação IRIS.

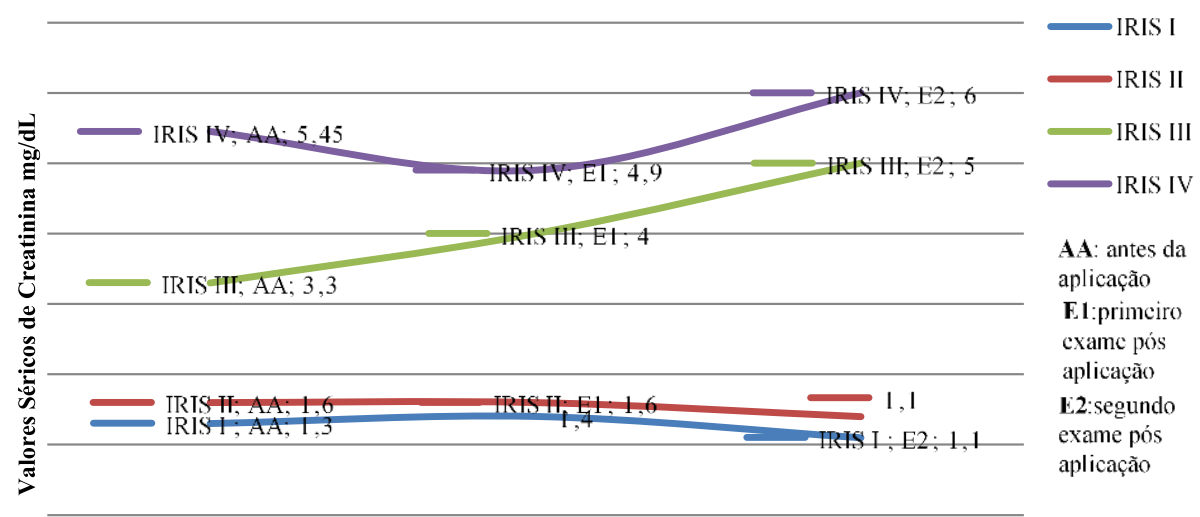

Transplante de células tronco

Gráfico 10. Gráfico referente à média dos valores séricos de creatinina em toda a amostra de acordo com cada estágio da classificação IRIS.

Grupo IRIS I: do primeiro exame antes do transplante celular para o primeiro exame depois do transplante houve uma queda na média do valor sérico de creatinina, porém no último exame esse valor aumentou novamente, terminando em $1,4 \mathrm{mg} / \mathrm{dL}$. Grupo IRIS II: houve uma redução na média do valor sérico de creatinina que finalizou em 1,4 mg/dL. Grupos IRIS III e IRIS IV: tiveram aumento na média do valor sérico de creatinina.

\section{Conclusão}

O estudo sugere que a terapia celular para tratamento de doença renal crônica gerou um resultado positivo, principalmente nos estágios menos avançados de lesão renal, pois houve diminuição expressiva dos níveis séricos de ureia e creatinina, marcadores de função renal mais utilizados na rotina clínica veterinária. Quando o paciente tratado já possuía um grau avançado de comprometimento dos rins, a resposta não foi tão positiva.

De modo geral, os resultados encontrados no estudo foram satisfatórios, porém pesquisas mais aprofundadas com dados controlados são de suma importância para avanços relacionados ao uso dessa promissora terapia.

Consideramos, portanto, que o transplante celular com células tronco pode trazer melhoria na qualidade de vida do paciente, sendo mais viável que outros tratamentos invasivos, como o transplante renal e a diálise peritoneal. Além disso, a medicina preventiva com o monitoramento geral da saúde, principalmente do animal idoso, se torna imprescindível para o tratamento precoce com resposta satisfatória.

\section{Referências}

Bortolotto, L. A. (2008). Hipertensão arterial e insuficiência renal crônica. Rev Bras Hipertens, 15(3), $152-155$.

Brum, A. M., Cintra, P. P., \& Mamão, L. D. (2012). Perfil eritrocitário e leucocitário de cães com doença renal crônica em relação à severidade da azotemia. Veterinária Notícias, 18(1).

IRIS. (2015). Staging of CKD.

Isola, J. G. M. P., Cadioli, F. A., \& Nakage, A. P. (2012). Erliquiose canina-revisão de literatura. Revista Científica Eletrônica de Medicina Veterinária, 18, 1-11.

Leal, V. O., Leite Júnior, M., \& Mafra, D. (2008). Acidose metabólica na doença renal crônica: abordagem nutricional. Revista de Nutrição, 21(1), 93-103. https://doi.org/10.1590/S141552732008000100010 
Levin, G., Belchior, G. G., Sogayar, M. C., \& Carreira, A. C. O. (2019). Medicina Regenerativa e Engenharia de Tecidos. Genética Na Escola, 14(1), 26.

Lima, M. M., Nuccio, J. C., Villalobos, M., Torres, C., \& Balladares, N. (2010). Sistema Renina Angiotensina y Riesgo Cardiometabólico. Revista Venezolana de Endocrinología y Metabolismo, $8(1), 3-10$.

Monteiro, B. S., Argolo Neto, N. M., \& Del Carlo, R. J. (2010). Células-tronco mesenquimais. Ciência Rural, 40(1), 238-245. https://doi.org/10.1590/S0103-84782010000100040

Morigi, M., \& Benigni, A. (2013). Mesenchymal stem cells and kidney repair. Nephrology Dialysis Transplantation, 28(4), 788-793. https://doi.org/10.1093/ndt/gfs556

Rufato, F. H. F., Rezende-Lago, N. C. M., \& Marchi, P. G. F. (2011). Insuficiência renal em cães e gatos. Revista Eletrônica da Univar, Barra Do Garças, 6, 167-173.

Silva, D., Rocha, F. P. C., Benedette, M. F., Santos, D. A. N., \& Costa, E. A. A. (2008). Insuficiência renal crônica em cães e gatos. Revista Científica Eletrônica de Medicina Veterinária, 6(11), 1-7.

Waki, M. F., Ribas Martorelli, C., Erdmann Mosko, P., \& Kogika, M. M. (2010). Classificação em estágios da doença renal crônica em cães e gatos: abordagem clínica, laboratorial e terapêutica. Ciência Rural, 40(10), 1-9.

Xing, L., Cui, R., Peng, L., Ma, J., Chen, X., Xie, R.-J., \& Li, B. (2014). Mesenchymal stem cells, not conditioned medium, contribute to kidney repair after ischemia-reperfusion injury. Stem Cell Research \& Therapy, 5(4), 101. https://doi.org/10.1186/scrt489

Zuttion, M. S. S. R., Wenceslau, C. V., Lemos, P. A., Takimura, C., \& Kerkis, I. (2013). Células-tronco de tecido adiposo e a importância da padronização de um modelo animal para experimentação préclínica. Revista Brasileira de Cardiologia Invasiva, 21(3), 281-287. https://doi.org/10.1590/S217983972013000300015

Histórico do artigo:

Recebido: 18 de novembro de 2020.

Aprovado: 7 de janeiro de 2021.
Licenciamento: Este artigo é publicado na modalidade Acesso Aberto sob a licença Creative Commons Atribuição 4.0 (CC-BY 4.0), a qual permite uso irrestrito, distribuição, reprodução em qualquer meio, desde que o autor e a fonte sejam devidamente creditados. 